\title{
Langmuir
}

pubs.acs.org/Langmuir

(C) 2009 American Chemical Society

\section{Improving Adsorbent Properties of Cage-like Ordered Amine Functionalized Mesoporous Silica with Very Large Pores for Bioadsorption}

\author{
Sandy Budi Hartono, ${ }^{\dagger}$ Shi Zhang Qiao, ${ }^{*}, \dagger$ Kevin Jack, ${ }^{*}$ Bradley P. Ladewig, ${ }^{\dagger}$ \\ Zhengping Hao, ${ }^{\S}$ and Gao Qing (Max) Lu*, \\ ${ }^{\dagger}$ ARC Centre of Excellence for Functional Nanomaterials, School of Engineering and Australian Institute \\ for Bioengineering and Nanotechnology, The University of Queensland, St. Lucia, QLD 4072, Australia, \\ *Centre for Microscopy and Microanalysis, The University of Queensland, St. Lucia, QLD 4072, Australia \\ and ${ }^{\S}$ Research Centre for Eco-Environmental Sciences, Chinese Academy of Sciences, Beijing 100085, \\ P.R. China
}

Received January 5, 2009. Revised Manuscript Received February 10, 2009

In this paper, we report the successful synthesis of amine-functionalized FDU-12-type mesoporous silica with a very large pore $(30.2 \mathrm{~nm})$ and a highly ordered mesostructure by using 3-aminopropyltriethoxysilane (APTES) as an organosilane source. Small angle X-ray scattering (SAXS) and transmission electron microscopy (TEM) measurements confirmed that the materials possessed a face-centered cubic (space group $F m \overline{3} m$ ) mesostructure. Different techniques were used to obtain a significant pore and entrance size enlargement: low synthesis temperature and high hydrothermal treatment temperature. The amount of amine organosilane influenced the mesostructure of the mesoporous silica. It was found that the addition of inorganic salt $(\mathrm{KCl})$ could help to maintain an ordered structure of the large pore mesoporous material. X-ray photoelectron spectroscopy (XPS), solid-state magic-angle spinning (MAS) ${ }^{13} \mathrm{C}$ nuclear magnetic resonance (NMR) and thermogravimetric analysis (TGA) verified the incorporation of amine functional groups on the surface of the materials. The addition of amine organosilane extended the synthesis temperature domain of ordered FDU-12 materials. The amine functional group significantly enhanced the adsorption capacity of the mesoporous materials, e.g., the amine functionalized mesoporous silica had 8-fold higher bovine serum albumin (BSA) adsorption capacity than that of the unfunctionalized one. It also had 2 times higher adsorption capacity for large cellulase enzymes. The amine functional group introduced positively charged groups on the surface of the mesoporous silica, which created strong electrostatic interactions between the protein and the silica.

\section{Introduction}

There has been ever increasing attention and effort in mesoporous material synthesis since the discovery of a new family of mesoporous silicas-M41S by Mobil researchers in 1992. ${ }^{1}$ Mesoporous silicas have many advantages such as narrow pore size distribution, tuneable pore size, large surface area, and the possibility to modify surface characteristics, which makes them promising applications as supports for biomolecule adsorption. $^{2-7}$ Diaz and Balkus were the first researchers in studying enzyme immobilization inside MCM-41. ${ }^{8}$ There was no adsorption for enzymes with molecular weight (MW) higher than $40 \mathrm{kDa}$, since the enzyme could not enter the pores of MCM-41. ${ }^{8}$ This research showed that larger pore mesoporous silica materials were needed as a host for biomacromolecules such as proteins (molecular

*Corresponding author. E-mail: s.qiao@uq.edu.au; maxlu@uq. edu.au.

(1) Kresge, C. T.; Leonowicz, M. E.; Roth, W. J.; Vartuli, J. C.; Beck, J. S. Nature 1992, 359, 710.

(2) Vallet-Regi, M.; Balas, F.; Arcos, D. Angew. Chem., Int. Ed. 2007, 46, 7548 .

(3) Blanco, R. M.; Terreros, P.; Fernandez-Perez, M.; Otero, C.; DiazGonzalez, G. J. Mol. Catal. B: Enzym. 2004, 30, 83.

(4) Kim, J.; Grate, J. W.; Wang, P. Chem. Eng. Sci. 2006, 61, 1017.

(5) Vinu, A.; Murugesan, V.; Tangermann, O.; Hartmann, M. Chem. Mater. 2004, 16, 3056.

(6) Bhattacharyya, S.; Lelong, G.; Saboungi, M. L. J. Exp. Nanosci. 2006, 1,375 .

(7) Hartmann, M. Chem. Mater. 2005, 17, 4577.

(8) Diaz, J. F.; Balkus, K. J. J. Mol. Catal. B: Enzym. 1996, 2, 115. size $3-30 \mathrm{~nm})$. The discovery of SBA-15 with pore sizes of $8-10 \mathrm{~nm}$ promoted more research in protein immobilization. ${ }^{9}$ Yiu et al. used unfunctionalized (pore size $5.6 \mathrm{~nm}$ ) and functionalized mesoporous SBA-15 (pore size $5.1 \mathrm{~nm}$ ) to adsorb a variety of proteins. The mesoporous silica showed high adsorption of cytochrome c, lyzozyme, myoglobin and $\beta$-lactoglobulin. Yet it had a low adsorption capacity for larger proteins (bovine serum albumin (BSA), ovalbumin and conalbumin) due to the pore exclusion effect. ${ }^{10}$

For enzyme immobilization inside mesoporous silica, pore size is a crucial factor. Small pores tend to limit the diffusion of enzyme through the pore, while large pores increase the possibility for enzyme immobilization. ${ }^{10^{-13}}$ Mesostructure also has a significant effect on bioadsorption. Cage-like porous structure made the material superior over one-dimensional structures such as MCM-41 and SBA-15, in terms of mass transfer and pore blocking. ${ }^{14}$ Fan et al. successfully synthesized an ordered mesoporous material (FDU-12), which possessed a cubic structure with three-dimensional connectivity. ${ }^{12}$

(9) Zhao, D. Y.; Feng, J.; Huo, Q. S.; Melosh, N.; Frederickson, G. H.; Chmelka, B. F.; Stucky, G. D. Science 1998, 279, 548.

(10) Yiu, H. H. P.; Botting, C. H.; Botting, N. P.; Wright, P. A. Phys. Chem. Chem. Phys. 2001, 3, 2983.

(11) Chong, A. S. M.; Zhao, X. S. Catal. Today 2004, 93-95, 293

(12) Fan, J.; Yu, C. Z.; Gao, F. T.; Lei, J.; Tian, B. Z.; Wang, L. M.; Luo, Q.; Tu, B.; Zhou, W. Z.; Zhao, D. Y. Angew. Chem., Int. Ed. 2003, 42, 3146.

(13) Yiu, H. H. P.; Wright, P. A. J. Mater. Chem. 2005, 15, 3690.

(14) Shui, W. Q.; Fan, J.; Yang, P. Y.; Liu, C. L.; Zhai, J. J.; Lei, J.; Yan, Y.; Zhao, D. Y.; Chen, X. Anal. Chem. 2006, 78, 4811. 
The FDU-12 mesoporous silica has been used for immobilizing lysozyme (spherical diameter $3.2 \mathrm{~nm}$ ) ${ }^{12}$ and to study the proteolysis mechanism using the protease enzyme. ${ }^{14}$ Recently, Fan et al. enlarged the pore of FDU-12 to very large pore size up to $27 \mathrm{~nm},{ }^{15}$ which provided an excellent adsorbent candidate to study adsorption, immobilization, and separation of large biomolecules.

Surface functionalization is necessary for improving the bonding between enzyme and the supporting material and creating a benign microenvironment for the enzyme. ${ }^{13}$ Functionalized mesoporous silica has unique characteristics compared to their predecessor (pure silica (PS)) and has wider applications including ion exchange, catalysis, and gas separation. ${ }^{16-19}$ In addition, functionalized mesoporous silica shows a higher protein adsorption capacity compared to the unfunctionalized one. ${ }^{10,11}$ Evidence has been found that immobilized protein inside functionalized mesoporous silica showed a higher activity compared to free enzyme. ${ }^{20}$

The organic functionalization of mesoporous materials has been demonstrated previously. ${ }^{21,22}$ Among the various organosilanes, those with amine functionality have received significant attention because of their vast range of applications. It is very useful in areas such as heterogeneous base catalysis, toxic arsenate ion trapping, support for metallic nanoparticles, sensors, and enzyme immobilization. ${ }^{23-25}$ Amine moiety has been incorporated in MCM-41-type mesoporous silica, ${ }^{26-30}$ although the limitation of these materials is their small pores, which inhibit their application in catalysis in particular. ${ }^{24}$ Amine functionalization of SBA-15-type mesoporous silica has been reported. ${ }^{23-25,31}$ However, it was found that the synthesis of ordered amine mesoporous silica under acidic conditions was disrupted by a protonation effect of the amine moiety. ${ }^{31}$ Several attempts have been tried to improve the ordered structure of the materials, such as changing the precursor to improve interactions between silicate and surfactant ${ }^{25}$ and using prehydrolysis of the silicate precursor. ${ }^{23}$ It was also found that the use of inorganic salt can greatly improve the ordered structure of amine mesoporous silica. $15,32,33$

(15) Fan, J.; Yu, C. Z.; Lei, J.; Zhang, Q.; Li, T. C.; Tu, B.; Zhou, W. Z.; Zhao, D. Y. J. Am. Chem. Soc. 2005, 127, 10794.

(16) Sayari, A.; Hamoudi, S. Chem. Mater. 2001, 13, 3151

(17) Hodgkins, R. P.; Garcia-Bennett, A. E.; Wright, P. A. Microporous Mesoporous Mater. 2005, 79, 241

(18) Huang, J. H.; Wu, T. H.; Wu, S. J.; Wang, H. S.; Xing, L. H.; Song, K.; Xu, H. Y.; Jiang, Y. Z.; Kan, Q. B. Mater. Chem. Phys. 2005, 94, 173.

(19) Clark, J. H.; Macquarrie, D. J. Chem. Commun. 1998, 853.

(20) Lei, C. H.; Shin, Y.; Magnuson, J. K.; Fryxell, G.; Lasure, L. L.;

Elliott, D. C.; Liu, J.; Ackerman, E. J. Nanotechnology 2006, 17, 5531.

(21) Stein, A.; Melde, B. J.; Schroden, R. C. Adv. Mater. 2000, 12, 1403.

(22) Vinu, A.; Hossain, K. Z.; Ariga, K. J. Nanosci. Nanotechnol. 2005, 5 , 347

(23) Wei, Q.; Nie, Z.-R.; Hao, Y.-L.; Liu, L.; Chen, Z.-X.; Zou, J.-X. J. Sol-Gel Sci. Technol. 2006, 39, 103.

(24) Mehdi, A.; Reye, C.; Brandes, S.; Guilard, R.; Corriu, R. J. P. New J. Chem. 2005, 29, 965.

(25) Sujandi; Park, S.-E.; Han, D.-S.; Han, S.-C.; Jin, M.-J.; Ohsuna, T. Chem. Commun. 2006, , 4131.

(26) Huh, S.; Wiench, J. W.; Yoo, J.-C.; Pruski, M.; Lin, V. S. Y. Chem Mater. 2003, 15, 4247.

(27) Munoz, B.; Ramila, A.; Perez-Pariente, J.; Diaz, I.; Vallet-Regi, M. Chem. Mater. 2003, 15, 500 .

(28) Etienne, M.; Lebeau, B.; Walcarius, A. New J. Chem. 2002, 26, 384.

(29) Yokoi, T.; Yoshitake, H.; Tatsumi, T. J. Mater. Chem 2004, 14, 951.

(30) Yokoi, T.; Yoshitake, H.; Yamada, T.; Kubota, Y.; Tatsumi, T. J. Mater. Chem. 2006, 16, 1125 .

(31) Chong, A. S. M.; Zhao, X. S. J. Phys. Chem. B 2003, 107, 12650.

(32) Yu, C. Z.; Tian, B. Z.; Fan, J.; Stucky, G. D.; Zhao, D. Y. Chem. Commun. 2001, 2726.

(33) Yu, C. Z.; Fan, J.; Tian, B. Z.; Stucky, G. D.; Zhao, D. Y. J. Phys Chem. B 2003, 107, 13368.
Some researchers have tried to improve the properties of FDU-12 through organic functionalization. Different organosilane compounds have been used to modify the FDU-12 surface. Kao et al. used vinyl $\left(\mathrm{CH}=\mathrm{CH}_{2}\right)$ to modify the surface of FDU-12, ${ }^{34}$ while Wright studied the incorporation of thiol $(-\mathrm{SH})$ in SBA-15 and FDU-12. ${ }^{17}$ Our group has previously made a preliminary study related to the adsorbent properties of amine mesoporous silica, which showed that the functionalization indeed increased the affinity of the materials for the protein. ${ }^{35}$

Organic functionalization can cause pore size reduction. As the amount of organosilane increases, the pore size tends to reduce. ${ }^{17,36-38}$ The incorporation of organic groups in the silica network may also change the pore structure and particle morphology of silica materials. ${ }^{17}$ Synthesis conditions of mesoporous silica such as synthesis temperature and hydrothermal treatment may affect the regularity of the pore distribution. $^{15,23}$ These indicate that many variables are involved in the synthesis of organic functional mesoporous silica and that further study is necessary to identify the optimum conditions to produce an ordered amine mesoporous silica, especially to synthesize the functionalized FDU-12 materials with very large pore (pore size $>10 \mathrm{~nm}$ ) at low temperature.

To the best of our knowledge, no detailed study has been done in investigating the synthesis conditions of ordered amine-functionalized FDU-12 silicas with very large pores and their adsorption of large biomolecules. In this paper, 3-aminopropyltriethoxysilane (APTES) was used to modify the mesoporous silica surface, and the enlargement of the pore was concurrently studied. We used low synthesis temperature (down to $10^{\circ} \mathrm{C}$ ) and high hydrothermal treatment temperature (up to $160{ }^{\circ} \mathrm{C}$ ) methods to produce highly ordered facecentered cubic (fcc) mesostructures (space group Fm3m) with very large pore size $(25.4-30.2 \mathrm{~nm})$ and entrance size $(9.0-10.8 \mathrm{~nm})$. Amine functionalization extended the synthesis temperature range of the original FDU-12 PS. In addition, we studied the effect of different compositions of organosilane on pore size and structure of silica. Of particular note, we found mesostructure improvement of the synthesized amine FDU-12 as a result of the addition of inorganic salt. In order to confirm the accessibility of the large pore and the adsorption properties of functionalized mesoporous silica, the synthesized materials were used in the adsorption of BSA $(4.0 \times 4.0 \times 14.0 \mathrm{~nm})$ and cellulase enzyme $(2.4-7.7 \mathrm{~nm})$

\section{Experimental Section}

Chemicals. Triblock poly(ethylene oxide)- $b$-poly(propylene oxide)- $b$-poly(ethylene oxide) copolymer $\mathrm{EO}_{106} \mathrm{PO}_{70} \mathrm{EO}_{106}$ (pluronic F127, MW = 13400), tetraethoxysilane (TEOS, 99\%), 1,3,5-trimethylbenzene (TMB), APTES, BSA (98\%), and Trichoderma reesei cellulase were purchased from Aldrich. All chemicals were used as received without purification.

Synthesis of Large Pore FDU-12 Silica (PS). In a typical synthesis, $1.0 \mathrm{~g}$ of $\mathrm{F} 127$ and $5.0 \mathrm{~g}$ of $\mathrm{KCl}$ were dissolved

(34) Kao, H.-M.; Chang, P.-C.; Wu, J.-D.; Chiang, A. S. T.; Lee, C.-H. Microporous Mesoporous Mater. 2006, 97, 9.

(35) Qiao, S. Z.; Zhang, H. Y.; Zhou, X. F.; Budihartono, S.; Lu, G. Q. Stud. Surf. Sci. Catal. 2007, 165, 425.

(36) Hoffmann, F.; Cornelius, M.; Morell, J.; Froeba, M. Angew. Chem. Int. Ed. 2006, 45, 3216 .

(37) Chong, A. S. M.; Zhao, X. S.; Kustedjo, A. T.; Qiao, S. Z. Microporous Mesoporous Mater. 2004, 72, 33.

(38) Chong, A. S. M.; Zhao, X. S. Appl. Surf. Sci. 2004, 237, 398. 
in $60.0 \mathrm{~mL}$ of $2.0 \mathrm{M} \mathrm{HCl}$. After $15 \mathrm{~min}$ stirring, $1.2 \mathrm{~g}$ of TMB was added and kept stirring for $6 \mathrm{~h}$. Then, $4.16 \mathrm{~g}$ of TEOS was added, and the stirring continued for $24 \mathrm{~h}$ at a reaction temperature (synthesis temperature) of $15{ }^{\circ} \mathrm{C}$. The molar ratio of reactants TEOS/F127/TMB/KCl/ $\mathrm{HCl} / \mathrm{H}_{2} \mathrm{O}$ was 1.00:0.0037:0.50:3.36: $6.00: 155$. All the solution along with the precipitate was transferred to an autoclave then heated at $160{ }^{\circ} \mathrm{C}$ (hydrothermal temperature) for $72 \mathrm{~h}$. The product was filtered and washed three times with ethanol and $\mathrm{HCl}(250 \mathrm{~mL}$ of ethanol and $2.0 \mathrm{~mL}$ of $2.0 \mathrm{M} \mathrm{HCl})$ at $60^{\circ} \mathrm{C}$ for $6 \mathrm{~h}$ to remove surfactant and then dried in air at room temperature.

Synthesis of Amine Functionalized Large Pore FDU-12 (Amine FDU-12). The basic process was the same with the synthesis of PS. The difference was that when TEOS was added to the solution, a certain amount of APTES was also added to the solution. The molar ratios of organosilane to TEOS were 1:20 (Organosilane: TEOS), 1:15, 1:10, and 1:7.5. The composition of other components (F127:TMB:KCl:HCl: $\left.\mathrm{H}_{2} \mathrm{O}\right)$ was kept constant. All the samples were denoted as APTES $X-Y-Z$. $X$ indicates a low synthesis temperature, and $Y$ represents a high hydrothermal treatment temperature, while $Z$ is the APTES/TEOS molar ratio. For example, APTES 15-160-1/10 means a sample prepared under the synthesis temperature of $15{ }^{\circ} \mathrm{C}$, hydrothermal treatment at $160{ }^{\circ} \mathrm{C}$, and organosilane composition 1:10 (APTES/TEOS). In this study, the synthesis temperatures 10,12 , and $15^{\circ} \mathrm{C}$ and hydrothermal treatment temperatures $100,130,150$ and $160^{\circ} \mathrm{C}$ were used in the materials synthesis.

Synthesis of As-Synthesized PS and Amine FDU-12. The synthesis was similar for the PS and Amine FDU-12, but without a thorough washing/extraction process. Thus, the surfactant was still within the mesoporous silica sample, indicating that the synthesized material did not have an open pore structure and only acquired an external surface. The as-synthesized material was only washed with a quick water rinse to remove the residues (acid, salt additive) on the external surface.

BSA Adsorption. The mesoporous silica materials were first degassed at $120^{\circ} \mathrm{C}$ overnight. Various concentrations of BSA solutions from 0.1 to $20.0 \mathrm{mg} / \mathrm{mL}$ were prepared. BSA was diluted in $0.01 \mathrm{M}$ acetate buffer at $\mathrm{pH} 4.7$. As much as $0.05 \mathrm{~g}$ of mesoporous silica was then mixed with $5.0 \mathrm{~mL}$ of BSA. The mixture was incubated in a water shaker for $24 \mathrm{~h}$ at $200 \mathrm{rpm}$ and room temperature $\left(20^{\circ} \mathrm{C}\right)$. The mixture was separated by centrifugation at $4750 \mathrm{rpm}$ and $20^{\circ} \mathrm{C}$ for $20 \mathrm{~min}$. Concentrations of BSA in solution, before and after incubation, were measured using UV-vis with a spectra wavelength at $280 \mathrm{~nm}$. All the samples' absorbance was converted to a concentration using the BSA standard curve measured in advance. The amount of BSA adsorbed was calculated by the difference in BSA concentration before and after adsorption. All the samples with a BSA concentration higher than $3.0 \mathrm{mg} / \mathrm{mL}$ were diluted to obtain a more accurate reading of absorbance. To determine the adsorption capacity, a curve of BSA loading and equilibrium solution concentration was constructed to get an adsorption isotherm. All adsorption data were then fitted using a Langmuir equation.

Cellulase Enzymes Immobilization. Trichoderma reesei cellulase solution was used as the enzyme source (ES). Different ratios of ES to citrate buffer ( $\mathrm{pH} 4.8$ ) were mixed to make 25.0 $\mathrm{mL}$ of mixed solution (E0). Five milliliters of E0 was collected for an initial concentration $\left(C_{0}\right)$ analysis. The remaining of 20.0 $\mathrm{mL}$ of E0 was then mixed with $0.1-0.2 \mathrm{~g}$ of mesoporous silica sample. Prior to immobilization, all the silica samples were degassed at $120^{\circ} \mathrm{C}$ overnight. The mixture of enzymes and silica was incubated for $24 \mathrm{~h}$ at $4{ }^{\circ} \mathrm{C}$ in a water shaker. After the incubation, the solutions were centrifuged and filtered. The clear part of solution (supernatant) was checked for enzyme concentration $\left(C_{\mathrm{t}}\right)$. The immobilized enzymes were washed three times followed by centrifuge and filtration before they were mixed with $5 \mathrm{~mL}$ of citrate buffer $(\mathrm{pH} \mathrm{4.8),} \mathrm{in} \mathrm{order} \mathrm{to} \mathrm{remove} \mathrm{the}$ loose bonding enzymes. The amount of adsorbed cellulase was determined by the Bradford method with BSA as a standard. The enzyme loading was determined from the different quantity in the enzyme solution before and after immobilization. All adsorption data were then fitted using a Langmuir equation.

Characterization. Small angle X-ray scattering (SAXS) measurements were performed on a Anton Paar/Panalytical $S A X$ Sess instrument using $\mathrm{Cu}-\mathrm{K} \alpha$ radiation $(\lambda=1.54056 \AA)$ at $40 \mathrm{kV}$ and $35 \mathrm{~mA}$. Transmission electron microscopy (TEM) images were obtained by a JEOL 1010 electron microscope with an acceleration voltage of $100 \mathrm{kV}$. Scanning electron microscopy (SEM) images were recorded on a JEOL 6300 microscope operated at $5-10 \mathrm{kV}$. Nitrogen sorption isotherms were obtained by a Quantachrome Quadrasorb SI analyzer at $77 \mathrm{~K}$. Before the measurements, the samples were degassed overnight at $120{ }^{\circ} \mathrm{C}$ in vacuum. The Brunauer-Emmett-Teller (BET) surface area was calculated using experimental points at a relative pressure of $P / P_{0}=0.05-0.25$. The total pore volume was calculated by the $\mathrm{N}_{2}$ amount adsorbed at the highest $P / P_{0}$ $\left(P / P_{0}=0.99\right)$. The pore size distribution was calculated by the Broekhoff-de Boer (BdB) method, ${ }^{39}$ using a spherical model. The cavity pore size and entrance pore size are determined from the adsorption and desorption branches, respectively. X-ray photoelectron spectroscopy (XPS) spectra were recorded on a Kratos Axis Ultra with a monochromatic Al K $\alpha$ X-ray source. Each spectrum was recorded at a survey scan from 0 to $1200 \mathrm{eV}$ with a dwell time of $100 \mathrm{~ms}$ and a pass energy of $160 \mathrm{eV}$ at steps of $1 \mathrm{eV}$ with one sweep. A high-resolution scan was conducted at a lower pass energy $(20 \mathrm{eV})$, a higher sweep, and a dwell time of $250 \mathrm{~ms}$. C1s with a binding energy of $285 \mathrm{eV}$ was used as the reference. A Shimadzu TGA $50 \mathrm{H}$ was used for thermogravimetric analysis (TGA) at a heating rate of $2{ }^{\circ} \mathrm{C} / \mathrm{min}$ under a nitrogen flow of $50 \mathrm{~mL} / \mathrm{min}$. Solid-state magic-angle spinning (MAS) ${ }^{13} \mathrm{C}$ nuclear magnetic resonance (NMR) measurements were performed with a Bruker MSL-300 spectrometer operating at a frequency of $75.482 \mathrm{MHz}$ for ${ }^{13} \mathrm{C}$. The spectrometer was equipped with a $4-\mathrm{mm}$ double air-bearing, MAS probe for MAS experiments. The proton $90^{\circ}$ pulse time used in the cross-polarization MAS (CPMAS) method was $5.5 \mu \mathrm{s}$, the acquisition time was $45 \mathrm{~ms}$, the cross-polarization time was $2 \mathrm{~ms}$, and the relaxation delay was $3 \mathrm{~s}$. The spectrum width was $50 \mathrm{kHz}$, and 4000 data points were collected over 2000 scans. Chemical shift of the ${ }^{13} \mathrm{C}$ spectrum was referenced to the resonance of adamantine at $38.23 \mathrm{ppm}$. All samples were equilibrated at room temperature $\left(22^{\circ} \mathrm{C}\right)$. Zeta potential measurements were conducted on a Zetasizer Malvern Instrument. An ultraviolet-visible absorbance spectrophotometer (JASCO-V550) was used to determine the concentration of BSA and cellulase in supernatant solution at 280 and $595 \mathrm{~nm}$, respectively.

\section{Results and Discussion}

Hydrothermal Treatment Temperature. Low synthesis temperature and high hydrothermal treatment temperature are the most influential factors for pore enlargement in the synthesis of FDU-12. ${ }^{12,15}$ Fan et al. studied different hydrothermal treatments from 100 to $140{ }^{\circ} \mathrm{C}$ in the FDU-12 PS synthesis. ${ }^{15}$ In our study, different hydrothermal treatment temperatures $\left(100,130,150\right.$, and $\left.160^{\circ} \mathrm{C}\right)$ were applied in the synthesis of amine FDU-12 materials. Figure 1 compares their SAXS spectra. PS (synthesized at a hydrothermal temperature of $160^{\circ} \mathrm{C}$ ) and APTES $15-100-1 / 15$ exhibits four peaks, which can be indexed to the $111,220,311$,

(39) Lukens, W. W.; Schmidt-Winkel, P.; Zhao, D. Y.; Feng, J. L.; Stucky, G. D. Langmuir 1999, 15, 5403. 


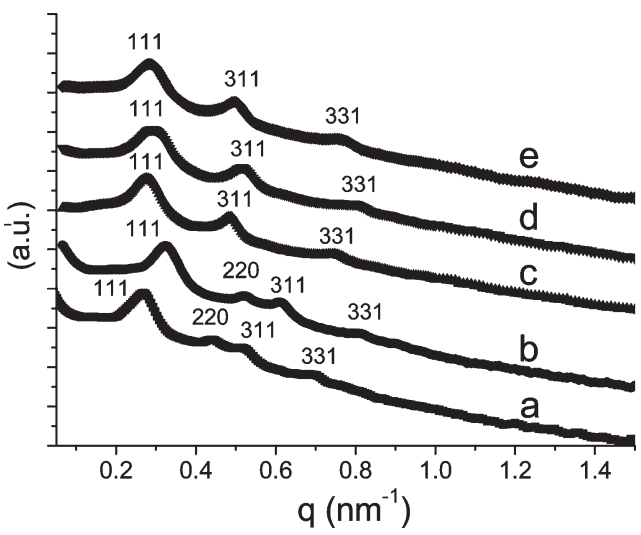

Figure 1. SAXS spectra of (a) FDU-12 PS synthesized at a reaction temperature of $15{ }^{\circ} \mathrm{C}$ and a hydrothermal temperature of $160{ }^{\circ} \mathrm{C}$, and amine FDU-12 synthesized at different hydrothermal temperatures: (b) APTES 15-100-1/15, (c) APTES $15-130-1 / 15$, (d) APTES $15-150-1 / 15$, and (e) APTES $15-160-$ $1 / 15$.

and $331 .{ }^{15}$ These peaks are a reflection of fcc mesostructure (space group $F m 3 m$ ). As the hydrothermal temperature increased, the peaks shifted to the left, showing that there was a pore enlargement. When a higher hydrothermal temperature of $160{ }^{\circ} \mathrm{C}$ was used, an ordered structure of amine FDU-12 can still be preserved. The SAXS analysis also showed that there were significant intensity differences of the 220 reflection for the samples synthesized at different hydrothermal temperatures. The 220 peak was minimized when the hydrothermal temperature was raised. This reflection is perpendicular to the direction of the entrance channel. The significant entrance pore enlargement has a considerable impact on the 220 reflection. That is, the samples with very large entrance sizes (APTES 15-130-1/15, APTES $15-150-1 / 15$, and APTES $15-160-1 / 15$ ) have a very low or even undetected reflection of 220 as compared to the sample of APTES 15-100-1/15, which is consistent with the observation by Zhao's group. ${ }^{40}$

Nitrogen adsorption-desorption equilibrium for amine FDU-12 samples prepared at different hydrothermal treatment temperatures (Figure 2) shows a type IV isotherm with a type $\mathrm{H} 2$ hysteresis loop, which is typical of mesoporous materials $^{37}$ with a cage-like structure. ${ }^{41}$ The adsorption isotherm curve of the amine FDU-12 sample shows a relatively sharp increase at around $P / P_{0}=0.85$, which confirms that the material possesses a uniform pore structure. This result is in agreement with the SAXS analysis. Figure 2 illustrates that, as the hydrothermal temperature increases, the desorption and adsorption isotherm curves are shifted to higher relative pressures. These shifts are attributed to the enlargement of the entrance pore and cavity sizes, respectively. ${ }^{12,41}$ Evidence of pore enlargement can also be clearly seen from the pore size distribution curves (inset of Figure 2).

Structure parameters of amine FDU-12 samples with large pores are listed in Table 1 . It can be seen that the increase in the hydrothermal temperature from 100 to $130{ }^{\circ} \mathrm{C}$ can improve the sample's entrance pore size to almost double

(40) Yu, T.; Zhang, H.; Yan, X. W.; Chen, Z. X.; Zou, X. D.; Oleynikov, P.; Zhao, D. Y. J. Phys. Chem. B 2006, 110, 21467.

(41) Matos, J. R.; Kruk, M.; Mercuri, L. P.; Jaroniec, M.; Zhao, L.; Kamiyama, T.; Terasaki, O.; Pinnavaia, T. J.; Liu, Y. J. Am. Chem. Soc. 2003, 125, 821 . from 4.8 to $8 \mathrm{~nm}$ ( $67 \%$ increase) and the cavity size from 19.5 to $27.9 \mathrm{~nm}$ ( $43 \%$ increase). It appears that the hydrothermal temperature does not have much influence on the cavity size compared to entrance size. This is consistent with other published results for mesoporous silica materials. ${ }^{12,40,42} \mathrm{Yu}$ et al. ${ }^{40}$ found that the increasing hydrothermal temperature from 100 to $130{ }^{\circ} \mathrm{C}$ caused a $16 \%$ increase in cavity size and $76 \%$ rise in entrance size. It is found in Table 1 that pore volume, cavity size, and surface area generally increase upon further increasing the hydrothermal temperature.

Hydrothermal treatment facilitates the completion of mesoporous silica framework formation. ${ }^{43}$ A change in the hydrothermal treatment temperature influences the hydrophobicity and hydrophilicity of a micelle. Hydrophobicity of micelle increases as temperature increases. The increase in temperature causes a reduction in hydrophilicity of poly (ethylene oxide) (PEO) block and pulls the PEO block back into the hydrophobic core, which results in a larger hydrophobic core. The increase in total hydrophobic volume occupies space in a less resistant region that is around the entrance size. ${ }^{40,44}$ This is believed to be the main reason for the significant change in entrance size. Kim et al. ${ }^{44}$ found a similar trend where the hydrothermal temperature and time affected the pore entrances and provided another perspective on entrance pore enlargement. They argued that, as the hydrothermal treatment temperature increased, the PEO blocks became less hydrophilic and reduced the interaction between the PEO block and the silicate source. This caused an aggregation of the PEO block on the adjacent side between the silica and the surfactant. The aggregation increased as the hydrothermal time increased. The space occupied by PEO aggregation became the pore entrance.

The enlargement in cavity size was followed by a wider pore distribution. The broad pore distribution was caused by a nonuniform cavity development during hydrothermal treatment at a high temperature. ${ }^{40,41}$ The largest entrance for all samples was achieved at a temperature of $160{ }^{\circ} \mathrm{C}$. In this research, the hydrothermal temperature of $160{ }^{\circ} \mathrm{C}$ was chosen for synthesis of the samples used in biomolecule adsorption.

SEM images in Figure 3A,B show that amine FDU-12 particles have a hexagonal-like morphology with size around $8-12 \mu \mathrm{m}$. The highly ordered mesostructures of amine FDU-12 are confirmed from TEM images taken along the direction of the pore axis and perpendicular to the pore (Figure 3C,D). Figure 3E,F shows TEM images of FDU-12 PS synthesized with hydrothermal treatment at $160{ }^{\circ} \mathrm{C}$. Compared with previously published results (hydrothermal treatment at $\left.140{ }^{\circ} \mathrm{C}\right),{ }^{14}$ it is found that the PS material prepared in this work maintains highly ordered mesostructure, indicating that hydrothermal temperature domain can further increase to $160^{\circ} \mathrm{C}$.

Synthesis Temperature. Figure 4A shows SAXS patterns of amine FDU-12 samples synthesized at different reaction temperatures $\left(10,12\right.$, and $\left.15^{\circ} \mathrm{C}\right)$. It shows that a relatively ordered structure can be preserved, even though the

(42) Kruk, M.; Matos, J. R.; Jaroniec, M. Colloids Surf., A: Physicochem. Eng. Aspects 2004, 241, 27.

(43) Karkamkar, A.; Kim, S.-S.; Pinnavaia, T. J Chem. Mater. 2003, 15, 11.

(44) Kim, T.-W.; Ryoo, R.; Kruk, M.; Gierszal, K. P.; Jaroniec, M.; Kamiya, S.; Terasaki, O. J. Phys. Chem. B 2004, 108, 11480. 


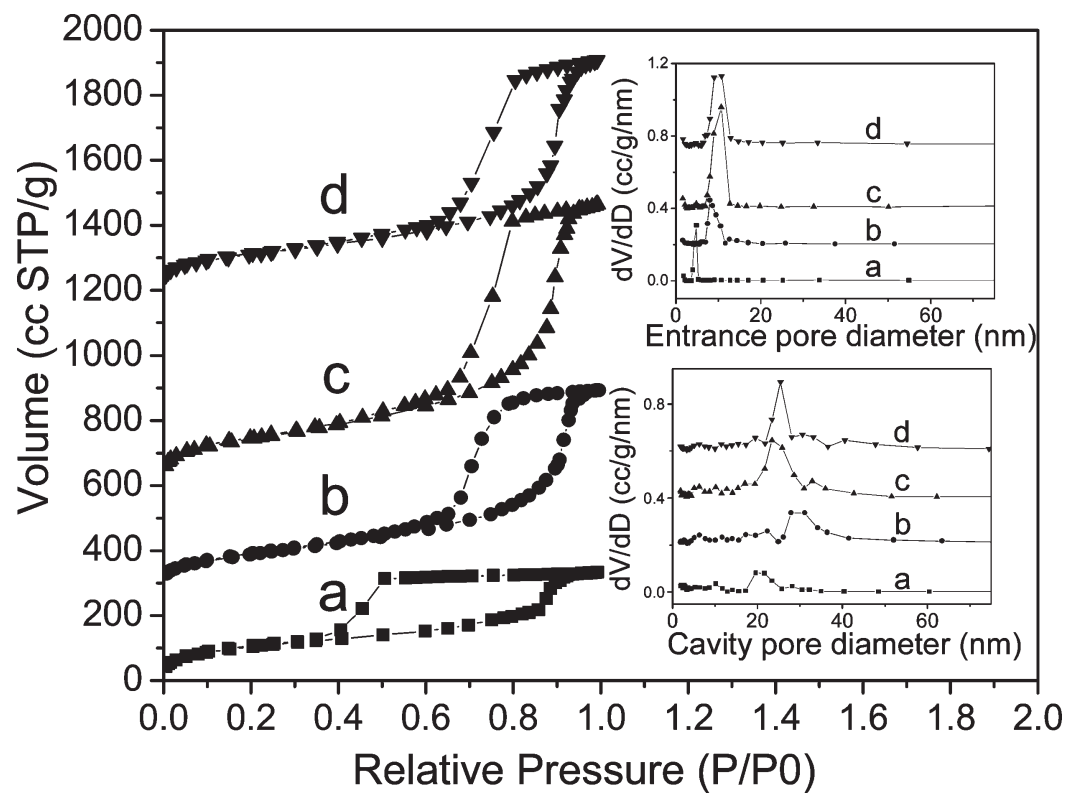

Figure 2. $\mathrm{N}_{2}$ sorption isotherms of amine FDU-12 samples synthesized at different hydrothermal temperatures: (a) APTES 15-100-1/15, (b) APTES 15-130-1/15, (c) APTES 15-150-1/15, and (d) APTES 15-160-1/15 (inset: cavity pore size or entrance pore size distribution). The isotherm curves b, c, and d are shifted by 300,600 , and $1200 \mathrm{cc} \mathrm{g}^{-1}$ STP, respectively, for clarity.

Table 1. Structure Parameters of Amine FDU-12 Samples with Super Large Pore Sizes

\begin{tabular}{|c|c|c|c|c|}
\hline \multirow[b]{2}{*}{ sample } & \multicolumn{2}{|c|}{ pore $\operatorname{size}^{a}(\mathrm{~nm})$} & \multirow[b]{2}{*}{ pore volume ${ }^{b}(\mathrm{cc} / \mathrm{g})$} & \multirow[b]{2}{*}{$\operatorname{BET}^{c}\left(\mathrm{~m}^{2} / \mathrm{g}\right)$} \\
\hline & cavity & entrance & & \\
\hline \multicolumn{5}{|c|}{ Hydrothermal Temperature Variations } \\
\hline PS & 28.0 & 10.8 & 1.03 & 271 \\
\hline APTES $15-100-1 / 15$ & 19.5 & 4.8 & 0.52 & 378 \\
\hline APTES $15-130-1 / 15$ & 27.9 & 8.0 & 0.92 & 345 \\
\hline APTES $15-150-1 / 15$ & 23.4 & 10.7 & 1.34 & 524 \\
\hline APTES $15-160-1 / 15$ & 25.4 & 10.8 & 1.10 & 403 \\
\hline \multicolumn{5}{|c|}{ Synthesis Temperature Variations } \\
\hline APTES $10-160-1 / 15$ & 30.2 & 9.0 & 0.93 & 386 \\
\hline APTES $12-160-1 / 15$ & 28.0 & 9.0 & 1.09 & 374 \\
\hline APTES $15-160-1 / 15$ & 25.4 & 10.8 & 1.10 & 403 \\
\hline \multicolumn{5}{|c|}{ Amine Organosilane Concentration Variations } \\
\hline APTES $15-160-1 / 20$ & 27.9 & 10.8 & 1.11 & 376 \\
\hline APTES $15-160-1 / 15$ & 25.4 & 10.8 & 1.10 & 403 \\
\hline APTES $15-160-1 / 10$ & 27.9 & 9.0 & 0.74 & 186 \\
\hline APTES $15-160-1 / 7.5$ & 25.6 & $10.8^{d}$ & 0.72 & 183 \\
\hline
\end{tabular}

${ }^{a}$ Pore size: cavity and entrance sizes are determined from the adsorption and desorption branches, respectively, using the BdB method. ${ }^{b}$ Total pore volumes are obtained at $P / P_{0}=0.99 .{ }^{c}$ BET specific surface areas are determined from the linear part of the BET equation $\left(P / P_{0}=0.05-0.25\right)$. ${ }^{d}$ The pore distribution is very wide.

synthesis temperature decreases to $10^{\circ} \mathrm{C}$. As the temperature decreases, the SAXS spectra peaks shift to the left, suggesting a cavity-pore enlargement. ${ }^{44}$ The relatively strong peaks of APTES $10-160-1 / 15$ and APTES $12-160-1 / 15$ indicate that the ordered structure of the mesoprous silica can still be maintained. This relatively ordered structure of amine FDU12 samples is an improvement over the original FDU-12, since it has been confirmed that the synthesis of FDU-12 PS at synthesis temperatures below $15^{\circ} \mathrm{C}$ only resulted in disordered materials. ${ }^{15}$ The introduction of APTES organosilane in the synthesis of FDU-12 mesoporous silica is believed to contribute to the structure improvement at low temperature.

Recently, our group has confirmed that the introduction of certain hydrophobic groups in the system of TEOS and F127 might improve the mesoporous silica structure at low synthesis temperature. ${ }^{45}$ In this study, the presence of

(45) Zhou, X. F.; Qiao, S. Z.; Hao, N.; Wang, X. L.; Yu, C. Z.; Wang, L. Z.; Zhao, D. Y.; Lu, G. Q. Chem. Mater. 2007, 19, 1870.
APTES with its long chain of hydrophobic propyl group and protonated amine groups ${ }^{31,46}$ induced a tighter aggregation of micelles, which supported the micelle formation even at a very low temperature. As a result, the relatively ordered structure of amine FDU-12 can be attained even at lower temperatures compared to the synthesis of original FDU-12 PS. ${ }^{45}$ The consequence of this stronger bonding reflects on the smaller pore size of the amine-FDU-12 compared to unfunctionalized FDU-12.

As the temperature decreases from 15 to $10{ }^{\circ} \mathrm{C}$, the adsorption curves of isotherms are shifted to the right (higher pressure) in Figure 4B, further confirming the enlargement of the cavity size. ${ }^{44}$ Low synthesis temperature triggers the formation of extra large pore size for FDU-12 PS. ${ }^{14}$ The low synthesis temperature can also enlarge the cavity size in our observation. For example, it can be enlarged from 25.4 to

(46) Krysztafkiewicz, A. J. Mater. Sci. 1987, 22, 478. 


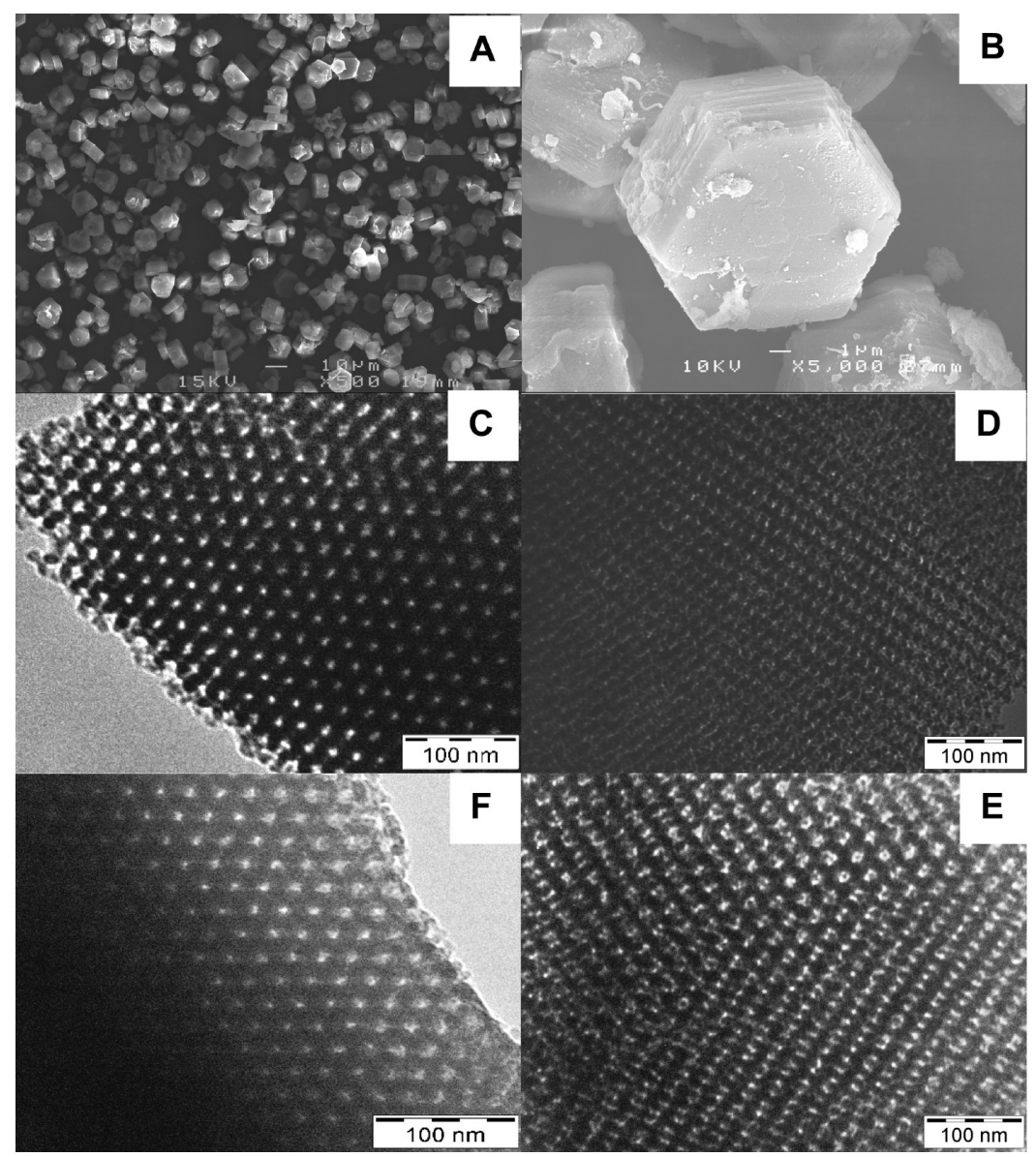

Figure 3. SEM images (A,B) and TEM images (C,D) of APTES 15-160-1/15, and TEM images of PS (E,F).

$30.2 \mathrm{~nm}$ with decreasing synthesis temperature from 15 to $10{ }^{\circ} \mathrm{C}$ (Table 1). As the synthesis temperature drops, micelles bonds are weakened, and more pore swelling agent TMB can be inserted inside the micelle's core, thus creating further enlargement.

TEM images of the amine FDU-12 samples synthesized at reaction temperatures of 10 and $12^{\circ} \mathrm{C}$ are shown in Figure 5. They indicate that the materials have not only very large pore sizes (30.2 and $28.0 \mathrm{~nm}$, Table 1) but also highly ordered mesostructure, confirming that the existence of APTES extends the reaction temperature range for the formation of ordered mesostructure, and both samples maintain fcc mesostructure. It is worth noting that APTES 10-160-1/15 possesses the largest pore size in the functionalized mesporous silica materials so far.

Different APTES Concentrations. It is known that, in the co-condensation method (one pot synthesis), organosilane concentration affects the mesoscopic order and pore size of the product. ${ }^{47,48}$ As the amount of organosilane compound increases, the less ordered mesoporous materials are produced. ${ }^{21}$ The SAXS patterns (Figure 6A) of amine FDU-12 samples synthesized at different compositions show that the increase of APTES organosilane concentrations from 1:20 to 1:15 (APTES/TEOS) does not disrupt the cubic structure $(F m 3 m)$ of the mesoporous silica. APTES 1:10 has a less intense SAXS peak compared to other low

(47) Hoffmann, F.; Cornelius, M.; Morell, J.; Froba, M. Angew. Chem. Int. Ed. 2006, 45, 3216 .

(48) Vinu, A.; Hossain, K. Z.; Ariga, K. J. Nanosci. Nanotechnol. 2005, 5 , 347 concentrations, indicating that the structure is less ordered. The increase in organosilane concentration means that more organic compounds are anchored in the silica matrix. This causes more interaction with the micelle block. The organosilane may not be distributed around the surface equally, thus giving different strength of interaction with the micelle block. On the other hand, the organic functional group in organosilane affects the cross-link of silica precursors. All these can interrupt the pore development from micelles, which leads to a less-ordered mesostructure. At the amine concentration of 1:7.5, the materials lose the ordered structure.

The nitrogen adsorption isotherms of amine FDU-12 samples synthesized at different compositions show that functionalization with different amine organosilane concentrations does not change the mesoporous structure of the materials (Figure 6B). Only APTES 15-160-1/7.5 shows distinct evidence of a disruptive effect as the organosilane composition increases. Its isotherm curve shows an illstructure, ${ }^{4,49}$ which indicates a disordered pore structure. All these observations are consistent with SAXS analysis results. The increase in amine organosilane concentration produces more protonated amine, which then interrupts the mesostructure.

As the amine organosilane concentration increases, the order area diminishes (see Figure S1 TEM images in the Supporting Information). It is difficult to find a long-range ordered structure for APTES 1:7.5, in contrast with

(49) Song, S. W.; Hidajat, K.; Kawi, S. Langmuir 2005, 21, 9568. 

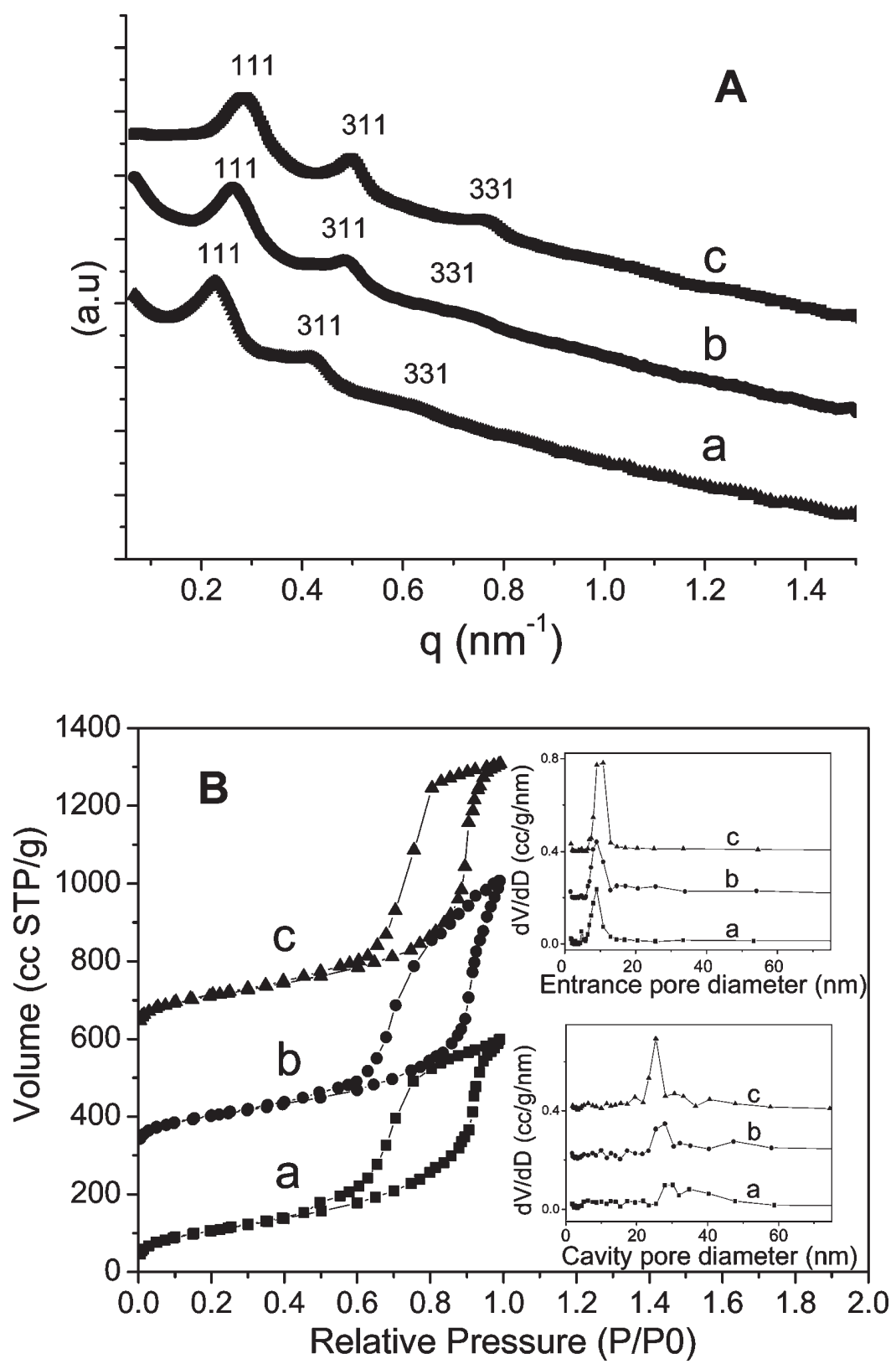

Figure 4. SAXS spectra (A) and $\mathrm{N}_{2}$ sorption isotherms (B) of amine FDU-12 samples synthesized at different reaction temperatures: (a) APTES 10-160-1/15, (b) APTES 12-160-1/15, and (c) APTES 15-160-1/15. (inset in B: cavity pore size distribution or entrance pore size distribution). The isotherm curves $\mathrm{b}$ and $\mathrm{c}$ are shifted by 300 and $600 \mathrm{cc} \mathrm{g}^{-1} \mathrm{STP}$, respectively, for clarity.

APTES 1:20. It shows that APTES 1:7.5 can not maintain an ordered structure. These results are in agreement with SAXS and nitrogen adsorption analysis.

Amine groups of APTES are easily protonated under acid conditions (very low $\mathrm{pH}$ ). ${ }^{31,50}$ In this research, the surface functionalized mesoporous silica was synthesized in $2.0 \mathrm{M} \mathrm{HCl}$ solution. Consequently, the increase in amine organosilane concentration would increase the possibility of amine becoming protonated. This phenomenon was confirmed through XPS analysis (Figure 7). There are two peaks in N1s spectra of amine FDU-12 samples, which represent $-\mathrm{NH}_{2}(399.8 \mathrm{eV})$ and $-\mathrm{NH}_{3}^{+}(401.9 \mathrm{eV})$. The $\mathrm{NH}_{3}^{+}$is believed to be the representative of protonated amine. ${ }^{31}$ As amine concentration increased from 1: 20 to 1: 7.5 ,

(50) Walcarius, A.; Etienne, M.; Lebeau, B. Chem. Mater. 2003, 15, 2161 . the composition of protonated amine $\left(-\mathrm{NH}_{3}^{+}\right)$elevated (Figure 7 and Table 2).

Zhao's group has made an excellent review related to the protonation effect in the synthesis of amine-functionalized SBA-15. ${ }^{31}$ Specifically, protonated amine within a silica matrix had several effects, which could result in matrix disruption. The positive charge of protonated amine could induce the formation of zwitterions $\left(-\mathrm{NH}_{3}^{+}-{ }^{-} \mathrm{OSi}\right) .{ }^{50}$ Second, the formation of large pore FDU-12 is similar to that of SBA-15, in that it follows the $\left(\mathrm{S}^{0} \mathrm{H}^{+}\right)\left(\mathrm{X}^{-} \mathrm{I}^{+}\right)$route under low $\mathrm{pH} .{ }^{9,51}$ Under this mechanism, the positive amine $\left(-\mathrm{NH}_{2} \mathrm{H}^{+}\right)$and the surfactant competed to interact with silica $\left(-\mathrm{SiOH}_{2}^{+}\right)$. The protonated amine $\left(-\mathrm{NH}_{2} \mathrm{H}^{+}\right)$had a tendency to form $\left(-\mathrm{NH}_{2} \mathrm{H}^{+}\right)\left(\mathrm{X}^{-} \mathrm{SiOH}_{2}^{+}\right)$complexes,

(51) Zhao, D. Y.; Huo, Q. S.; Feng, J. L.; Chmelka, B. F.; Stucky, G. D. J. Am. Chem. Soc. 1998, 120, 6024. 


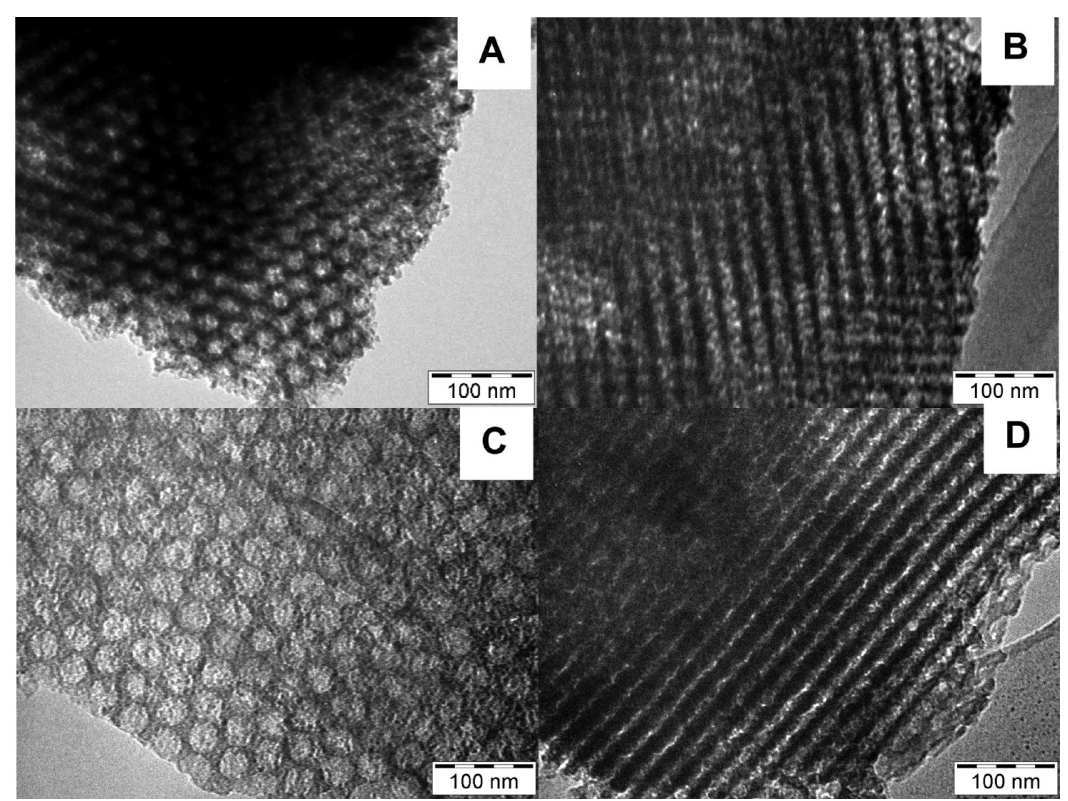

Figure 5. TEM images of amine FDU-12 samples synthesized at different reaction temperatures: APTES 12-160-1/15 (A,B) and APTES 10$160-1 / 15$ (C,D).

which led to less interaction of surfactant micelle and silicate. ${ }^{31}$ These effects weakened the interaction between the silicate and the surfactant, which led to a disordered structure formation.

Effect of Inorganic Salts. Previous research showed the disordered-structure of amine-functionalized mesoporous silica, even at a low amine concentration of 1:20 (APTES/ TEOS). ${ }^{31}$ The protonated amine under acid conditions was believed to bring the disruptive effect in the self-assembly of mesoporous silica structure. In this research, as can be seen in Figure 6 and Figure S1 in the Supporting Information, the highly ordered amine mesoporus silica can still be maintained at the composition up to 1:10 (APTES/TEOS). The weaker interaction of silicate and the hydrophilic part of the surfactant, which is caused by the protonated amine group, can be minimized with the presence of inorganic salts. The inorganic salts $(\mathrm{KCl})$ improved the interaction between the silicate species and the nonionic block copolymer, which increased the ordered structure of the mesoporous silica. ${ }^{15,32,33}$

${ }^{13} \mathrm{C}$ NMR Spectra and TGA. Figure 8A shows ${ }^{13} \mathrm{C}$ NMR spectra of APTES 15-160-1/15. Three peaks at 8.4, 25.2 , and $40.7 \mathrm{ppm}$ denote the presence of three different carbon chemical environments: $\mathrm{C} 1, \mathrm{C} 2$, and $\mathrm{C} 3$ as shown in Figure $8 \mathrm{~A} .{ }^{37}$ The peaks at around $64.1-78.0 \mathrm{ppm}$ are attributable to the surfactant remained in the sample. The existence of other peaks at 15.6 and $57.3 \mathrm{ppm}$ indicates the ethoxy group resulting from incomplete hydrolysis of TEOS or ethanol residues from the extraction process to remove surfactant. 37,38

TGA results also confirm the existence of the surfactant (Figure 8B). Degradation at around $200-350{ }^{\circ} \mathrm{C}$ is related to the removal of the remaining surfactant. ${ }^{34,52,53}$ It shows that around $8 \%$ of the surfactant still remains in the mesoporous silica. ${ }^{37,49}$ The water evaporation causes the degradation at around $100{ }^{\circ} \mathrm{C} .{ }^{54}$ Continual silicate condensation

(52) Steel, A.; Carr, S. W.; Anderson, M. W. Chem. Mater. 1995, 7, 1829.

(53) Kao, H.-M.; Wu, J.-D.; Cheng, C.-C.; Chiang, A. S. T. Microporous Mesoporous Mater. 2006, 88, 319.

(54) Lim, M. H.; Stein, A. Chem. Mater. 1999, 11, 3285. contributes to the weight loss at $400-600{ }^{\circ} \mathrm{C} .{ }^{52}$ The differential thermal analysis (DTA) curve shows an extremely intense exothermic peak at $343{ }^{\circ} \mathrm{C}$, which corresponds to the thermal decomposition of protonated amines $\left(-\mathrm{CH}_{2} \mathrm{CH}_{2} \mathrm{CH}_{2} \mathrm{NH}_{3}^{+}\right) \cdot{ }^{31,55}$

BSA Adsorption. The bioadsorption properties of amine FDU-12 mesoporous silica with large pores were tested using BSA as a model adsorbate. BSA has dimensions of $40 \times 40 \times$ $140 \AA^{3}$ and an MW of $69 \mathrm{kDa} \cdot{ }^{56}$ It is proposed that BSA is able to enter into the pore of amine FDU-12 synthesized in this research.

Figure 9 shows adsorption isotherms of BSA on different mesoporous silica samples under a $\mathrm{pH}$ value of 4.7. It illustrates a comparison of BSA adsorption against FDU12 PS and amine FDU-12 samples with different cavity sizes and entrance sizes. APTES $10-160-1 / 15$ had the highest BSA adsorption amount of $286.96 \mathrm{mg} \mathrm{BSA} / \mathrm{g}$; by contrast, APTES $15-130-1 / 15$ had the lowest adsorption amount with $50.72 \mathrm{mg} / \mathrm{g}$. The increase in amine FDU-12 cavity size from 25.4 (APTES $15-160-1 / 15$ ) to $30.2 \mathrm{~nm}$ (APTES 10-160-1/15) elevated the BSA adsorbed amount (Figure 9, Table 3). The low adsorbed amount of APTES $15-130-1 / 15$ is due to its small entrance size $(8 \mathrm{~nm})$, which limited subsequent BSA molecule entrance to the cavity once the entrance was occupied by one BSA molecule. It was found by comparing the adsorbed amount on PS and the APTES 12-160-1/15 sample (same cavity size) that the loading amount of BSA on PS was much smaller than those on functionalized materials.

The strong electrostatic interaction between amine FDU12 and BSA is believed to be the main reason for its high adsorption capacity. The electrostatic charge of BSA at $\mathrm{pH} 4.7$ was determined by measuring the zeta potential. The BSA had a negative charge at $-7.39 \mathrm{mV}$, which can explain

(55) Zhang, X.; Wu, W. J.; Wang, J. F.; Liu, C. L. J. Am. Ceram. Soc. 2007, 90,965 .

(56) Katiyar, A.; Ji, L.; Smirniotis, P. G.; Pinto, N. G. Microporous Mesoporous Mater. 2005, 80, 311. 

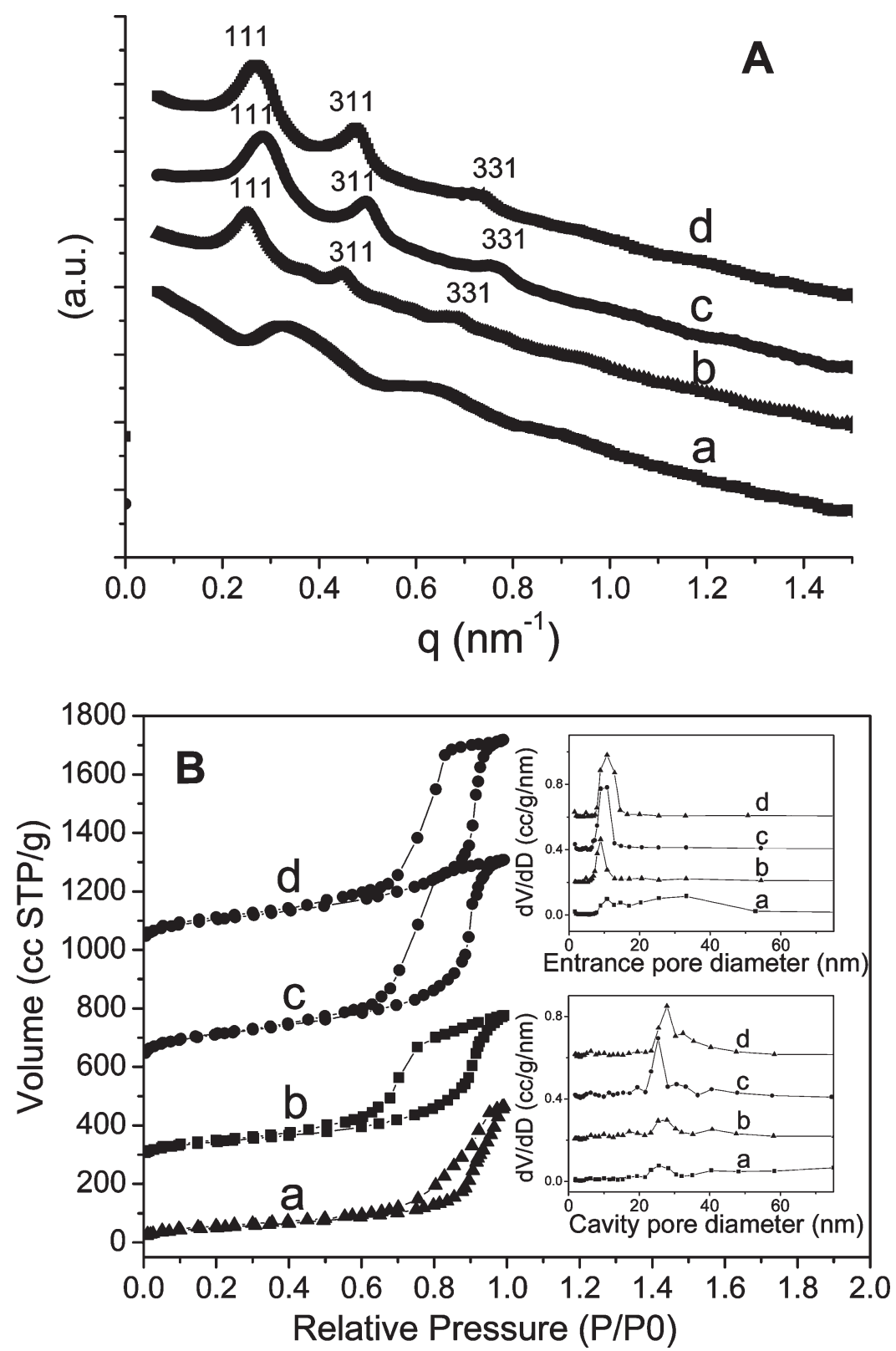

Figure 6. SAXS spectra (A) and $\mathrm{N}_{2}$ sorption isotherms (B) of amine FDU-12 samples synthesized with different amount of APTES: (a) APTES 15-160-1/7.5, (b) APTES 15-160-1/10, (c) APTES 15-160-1/15, and (d) APTES 15-160-1/20. (inset in B: cavity pore size or entrance pore size distribution). The isotherm curves b, c, and d are shifted by 300,600 , and $1000 \mathrm{cc} \mathrm{g}^{-1}$ STP, respectively, for clarity.

why amine FDU-12 with a positive charge $(+5.87 \mathrm{mV})$ attracted more BSA compared to PS with negative charge $(-7.34 \mathrm{mV})$.

To confirm BSA adsorption on the external surface or into the pores of materials, as-synthesized APTES $15-160-1 / 15$ and as-synthesized PS were also used as adsorbents to study BSA adsorption. The SEM images of both APTES 15-160-1/15 and its as-synthesized sample (Figure S2 in the Supporting Information) clearly show their opening and blocked pore structures, respectively. On the basis of the adsorption data in Table 3 derived from isotherms shown in Figure 10 for both as-synthesized and surfactant-removed samples, the fractions of BSA adsorbed on the outer surfaces were calculated to confirm that approximately only $17.5 \%$ of BSA $(6.36 \mathrm{mg} / \mathrm{g})$ was adsorbed on the outer surface of PS as compared to the total BSA amount adsorbed on the
PS (36.14 g/g). The BSA was successfully loaded inside the material's pore (approximately $29.8 \mathrm{mg} / \mathrm{g}$ ) with an entrance size $10.8 \mathrm{~nm}$ and cavity size $28.0 \mathrm{~nm}$. On the other hand, APTES 15-160-1/15 adsorbed about $75 \%$ of BSA on the outer surface $(100.0 \mathrm{mg} / \mathrm{g})$, while the remaining BSA (about $32.57 \mathrm{mg} / \mathrm{g}$ ) was located on the internal surface or inside the pore. The positive charge of the amine moiety group on the external surface of APTES was easily accessible for BSA, compared to the internal surface. The BSA molecule transfer inside the pore was hindered by blockage and repulsion effect from the biomolecules, which were already adsorbed on the internal surface of the pore. This reduced the adsorption on the internal surface. The large amount of BSA on the external surface shows a remarkable improvement of adsorbent properties of the functionalized materials. 


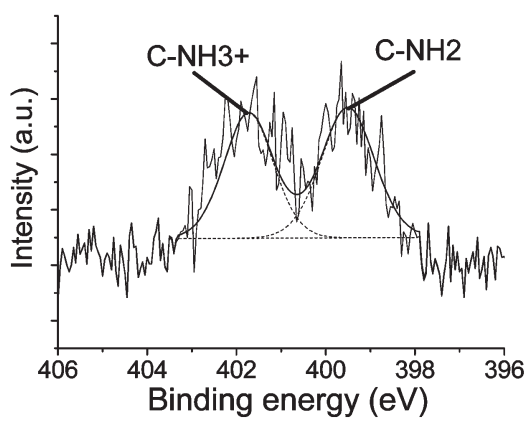

A

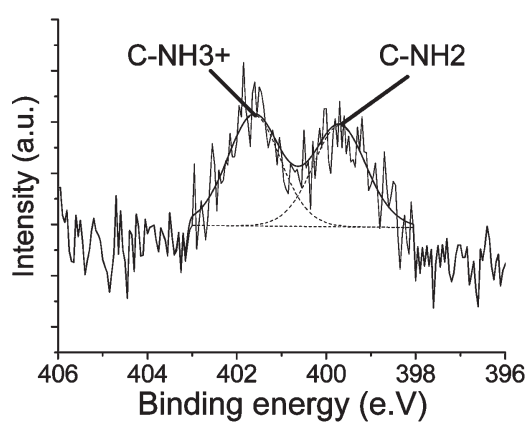

$\mathrm{C}$

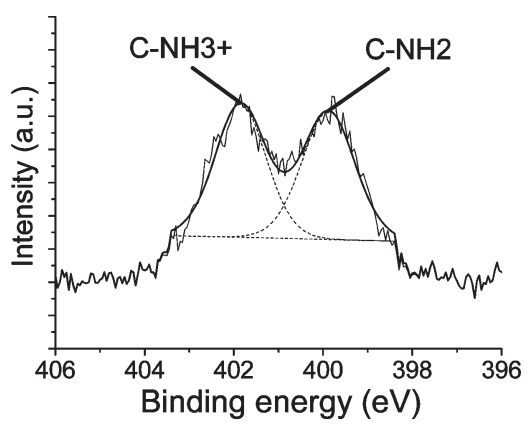

B

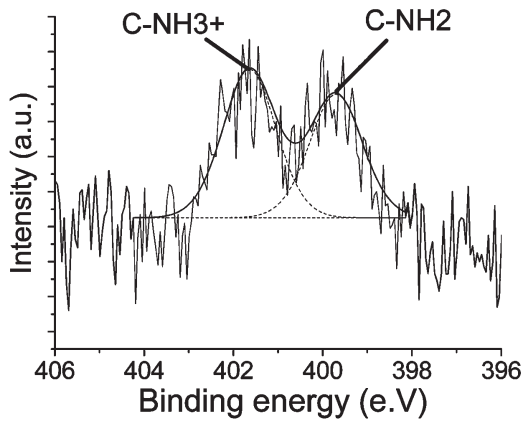

D

Figure 7. XPS analysis (N1s spectra) of amine FDU-12 samples synthesized with different amount of APTES: (A) APTES 15-160-1/20, (B) APTES 15-160-1/15, (C) APTES 15-160-1/10, and (D) APTES 15-160-1/7.5.

Table 2. N1s Spectra Composition of Amine and Protonated Amine Groups for Amine FDU-12 Samples Synthesized with Different Amount of APTES

\begin{tabular}{ccc}
\hline sample & $\begin{array}{c}-\mathrm{NH}_{2}(399 \mathrm{eV}) \\
\text { in } \% \text { area }\end{array}$ & $\begin{array}{c}-\mathrm{NH}_{3}^{+}(401 \mathrm{eV}) \\
\text { in \% area }\end{array}$ \\
\hline APTES $15-160-1 / 20$ & 53.86 & 46.14 \\
APTES $15-160-1 / 15$ & 49.94 & 50.06 \\
APTES $15-160-1 / 10$ & 47.78 & 52.22 \\
APTES $15-160-1 / 7.5$ & 45.44 & 54.56
\end{tabular}

Cellulase Enzyme Immobilization. Cellulase or cellulolytic enzymes are water-soluble protein molecules. Cellulase enzymes are responsible for cellulose hydrolysis. The structure of the enzymes is in the form of sphere or ellipsoid. In the spherical structure, cellulase has dimensions around 24-77 $\AA$, while, for ellipsoidal structure, the dimension is between $13 \times 79 \AA$ and $42 \times 252 \AA .{ }^{57}$

Figure 11 shows cellulase enzymes adsorption on PS, APTES 15-160-1/15, and their as-synthesized forms. Their saturation adsorption amounts are also listed in Table 3. The results show that amine FDU-12 (APTES 15-160-1/15) with a positive charge has a higher adsorption amount than PS (negatively charged). The cellulase adsorption was conducted at a $\mathrm{pH}$ solution of 4.8. Zetasizer analysis confirmed that the charge value of cellulase at $\mathrm{pH} 4.8$ was of $-6.02 \mathrm{mV}$, which showed that cellulase had a counterpart charge with amine silica. Obviously the negatively charged PS led to a lower adsorption

(57) Cowling, E. B.; Kirk, T. K. In Enzymatic Conversion of Cellulosic Materials: Technology and Applications: Symposium Proceedings; Wiley (in cooperation with the National Academy of Sciences) : New York, 1976; pp95-123. amount of cellulase. The cellulase adsorption (Figure 11, Table 3) using as-synthesized PS or as-synthesized APTES $15-160-1 / 15$ as adsorbents confirmed that around $50 \%$ of cellulase was adsorbed on the external surface of both samples, while the remainder existed inside the pores.

\section{Conclusion}

Highly ordered large-pore amine-functionalized FDU12 was synthesized with the support of inorganic salt $(\mathrm{KCl})$ at low reaction temperatures $\left(10-15^{\circ} \mathrm{C}\right)$ and high hydrothermal temperature (up to $160^{\circ} \mathrm{C}$ ). The presence of amine groups extended the synthesis temperature domain to obtain ordered mesostructured materials compared to the synthesis of original FDU-12 PS. APTES, with its long chain of hydrophobic propyl group, induced a tighter aggregation of micelle, which supported the micelle formation even at a very low temperature. The inorganic salt improved the interaction between silicate, protonated amine, and surfactant which helped maintain an ordered mesostructure at low $\mathrm{pH}$ value (strong acid condition). The addition of amine group influenced the ordered structure of the materials and led to smaller pore size. The synthesis and hydrothermal temperatures had significant effects on enlargements of pore and entrance sizes. The pore size (cavity and entrance) and the surface properties of the synthesized mesoporous silica significantly influenced the protein adsorption amount. The amine functionalized FDU-12 had an 8 times higher BSA adsorption capacity and twice the cellulase enzyme adsorption capacity compared to PS. Most of BSA and cellulase enzyme were adsorbed on the external surface of amine-functionalized FDU-12 materials 

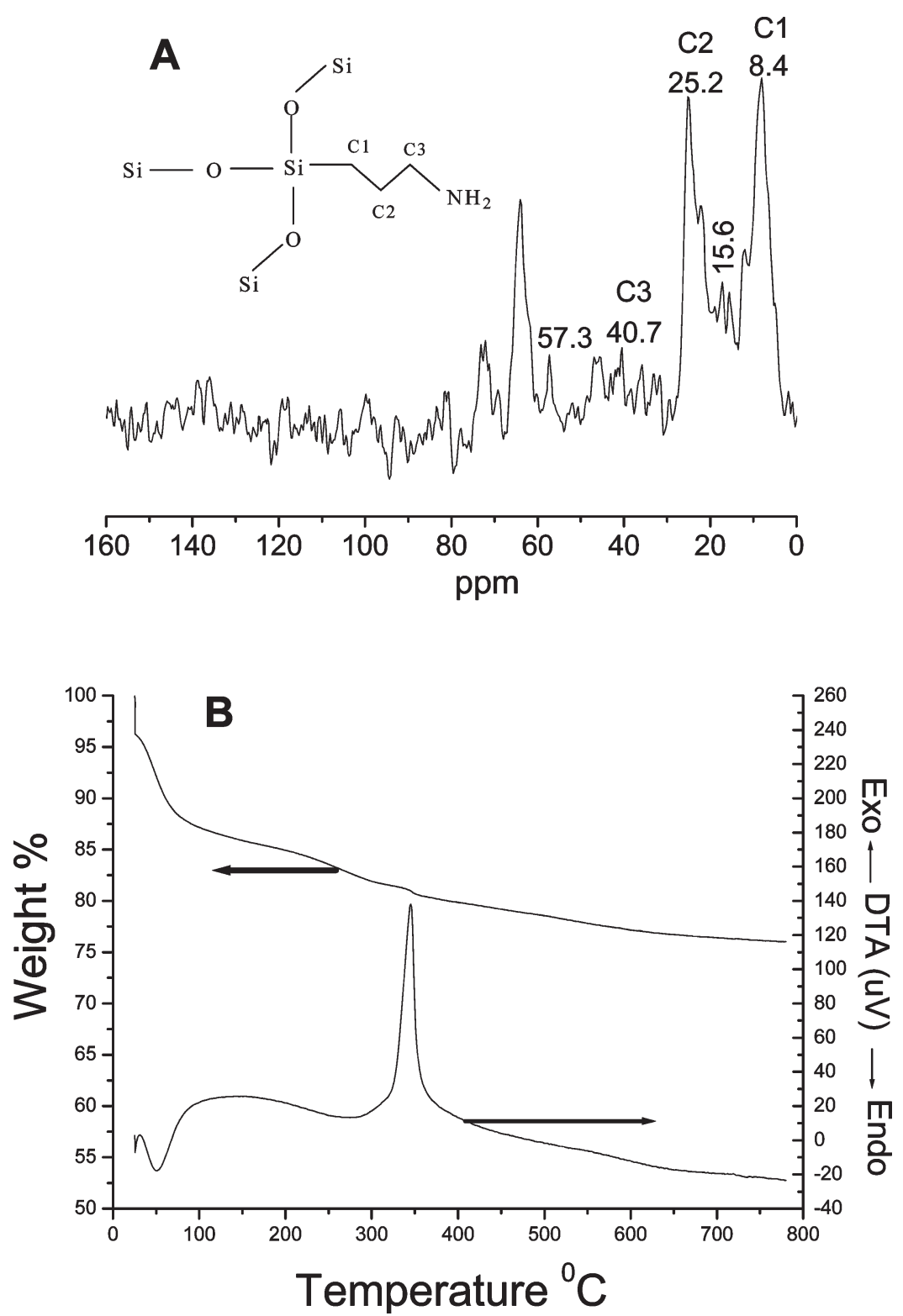

Figure 8. (A) ${ }^{13} \mathrm{C}$ NMR spectra (B) TGA analysis of the sample APTES $15-160-1 / 15$.

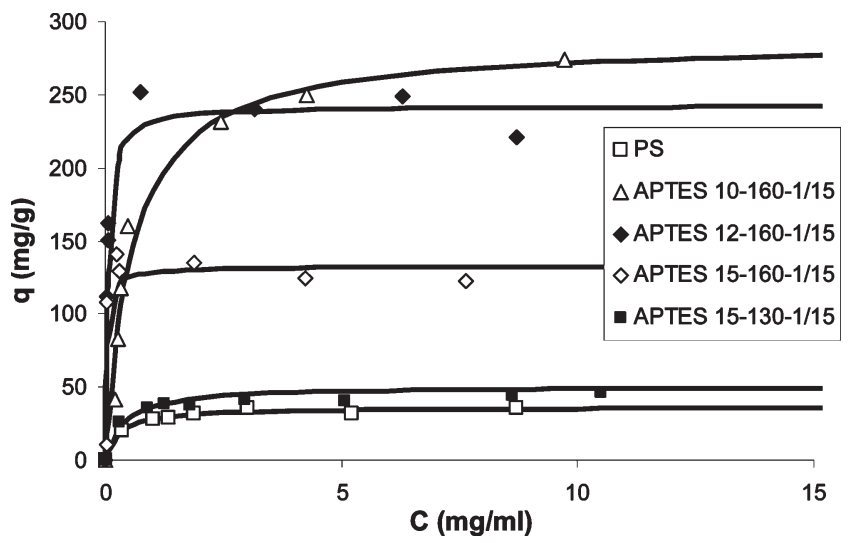

Figure 9. Adsorption isotherms of BSA on FDU-12 PS and amine FDU-12 samples with different cavity and entrance sizes (at $20^{\circ} \mathrm{C}$ ).

because of strong electrostatic force between biomolecules and material's surface as well as the blockage and repulsion effects among biomolecules.
Table 3. BSA and Cellulase Enzyme Adsorption Data on FDU-12 PS, Amine FDU-12, and Their As-Synthesized Forms

\begin{tabular}{llc}
\hline \multicolumn{1}{c}{ sample } & \multicolumn{1}{c}{$\begin{array}{c}\text { BSA adsorption } \\
q_{\mathrm{m}}(\mathrm{mg} / \mathrm{g})\end{array}$} & $\begin{array}{c}\text { cellulase adsorption } \\
q_{\mathrm{m}}(\mathrm{mg} / \mathrm{g})\end{array}$ \\
\hline PS & 36.14 & 10.35 \\
PS as-synthesized & $6.36(17.5 \%)^{a}$ & 4.24 \\
APTES 15-160-1/15 & 132.57 & 21.80 \\
APTES 15-160-1/15 & $100.00(75.0 \%)^{a}$ & 12.85 \\
as-synthesized & & \\
APTES 12-160-1/15 & 242.53 \\
APTES 10-160-1/15 & 286.96 \\
APTES 15-130-1/15 & 50.72 \\
\multicolumn{2}{c}{${ }^{a}$ The adsorption percentage on the outer surface is determined by } \\
comparing the BSA adsorbed amount on the PS as-synthesized (or \\
APTES 15-160-1/15 as-synthesized) sample and the BSA adsorbed \\
amount on PS (or APTES 15-160-1/15).
\end{tabular}

Acknowledgment. This work was financially supported by the Australian Research Council (ARC) through Discovery and Linkage Project programs, a UQ Mid-Career Research Fellowship for S.Z.Q., and the ARC Centre of 


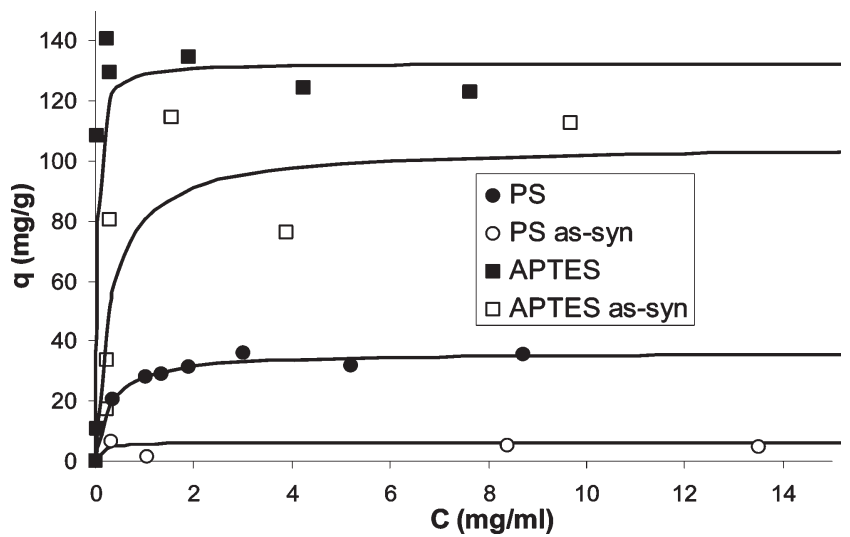

Figure 10. Comparison of BSA adsorption on PS, APTES $15-160-1 / 15$, and their as-synthesized forms.

Excellence for Functional Nanomaterials. We thank Professor Andrew Whittaker and Dr. Ekaterina Strounina from The Centre of Magnetic Resonance for their help on NMR measurements. The support of Dr. Barry Wood from The Brisbane Surface Analysis Facility in XPS analysis is acknowledged.

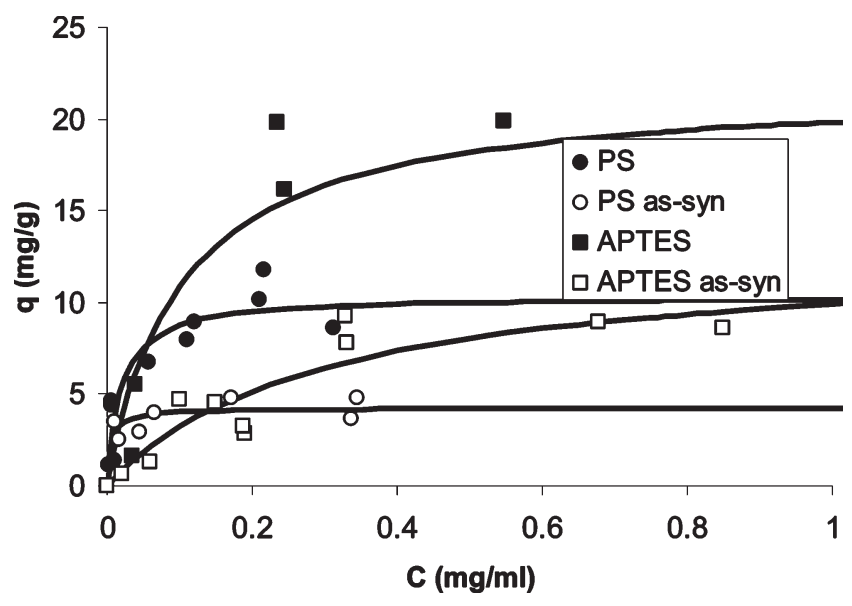

Figure 11. Adsorption isotherms of cellulase on PS, APTES 15-160-1/15, and their as-synthesized forms (at $4{ }^{\circ} \mathrm{C}$ ).

Supporting Information Available: TEM images of amine FDU-12 samples synthesized with different amount of APTES, and high-resolution SEM images of amine FDU12 samples. This material is available free of charge via the Internet at http://pubs.acs.org. 